\title{
Three Rooted Maxillary Second Premolar: A Rare Clinical Finding
}

\author{
AJAY JAIN*1, RANJANA GUPTA²
}

Endodontic failure can be due extra canals in the root morphology left untreated by the clinician. Careful assessment and modifications may be required in the cavity preparation for stress free entry to complex root anatomy. This case report depicts a 36- year old male with three roots in his maxillary second molar

KEYWORDS: Maxillary Second Premolar, Three Rooted, Endodontic, Treatment, RCT

\section{INTRODUCTION}

For a clinician to provide a successful and pain-free endodontic experience, it is important that he is wellversed with the morphology of the tooth as at times, there are certain variations in the tooth anatomy that if left unnoticed, shall cause a lot of discomfort to the patient. ${ }^{1,2}$

In conjunction to this, a successful endodontic treatment depends on a correct diagnosis with appropriate cleaning and shaping of the root canal system by the clinician. ${ }^{3}$ Three rooted molars are also referred to as mini-molars and radiculous teeth. ${ }^{4}$ The incidence of three canals in maxillary first and second premolars were reported as $5 \%$ and $1 \%$, by Vertucci and colleagues.

This case report aimed to present a rare clinical case reporting a rare anatomical variation of premolar with 3 roots and 3 root canals.

\section{CASE REPORT}

A 36-year-old male patient reported to a dental clinic of a chief complaint of pain upon chewing, hot and cold sensation in his upper back left region tooth. Upon a detailed clinical examination, the tooth 25 was carious with a positive sign of tenderness upon percussion. A Periapical radiograph in relation to the same tooth showed that the tooth 25 was having 3 roots with irreversible pulpitis and also there was widening of the periodontal ligament as seen in figure 1.

The treated course was decided upon recording a thorough medical and past dental history was taken which was non-contributory in nature. Before treatment, we obtained a written, informed consent of the patient. The treatment was initiated by giving
Local anaesthesia, and the tooth was isolated using a rubber dam and coronal access cavity was done, two buccal canals and one palatal canal was located; the pulp was entirely extirpated, working length of all three canals were determined using radiograph. [Figure 2]. Preparation of all the three canals was done upto 35 no. file using hand on instrument (k-files) with copious irrigation with $2.5 \%$ sodium hypochlorite and saline. Chlorhexidine $0.2 \%$ was used as a final irrigation material.

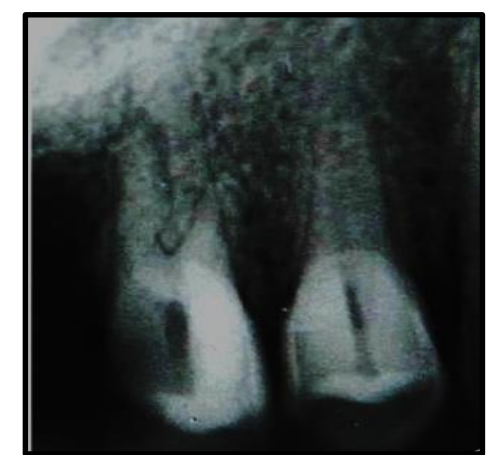

Figure 1: Pre-operative intraoral periapical view of tooth number 25.

The root canals were properly dried with absorbent paper points and appropriate Gutta Percha (GP) mastercones (manufacturer: Sure endo) were selected. Obturation of the root canals were carried out by the cold lateral condensation technique with GP cones along with an endomethasone sealer being used to seal the canal. Restoration of the tooth was carried out using amalgam restoration and the patient was advised for crown in the same tooth, which was delivered successively with no further complications. 
After a six months follow up, the patient is undergoing regular dental check-ups once every six months and is contended with the treatment provided.

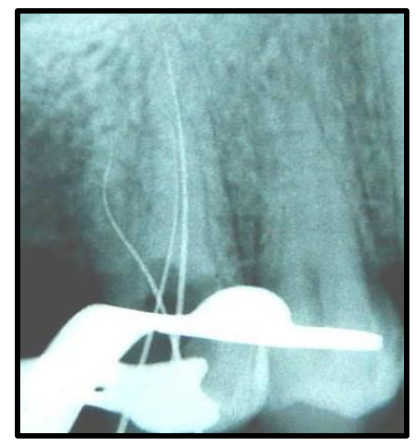

Figure 2: Working length of all the three canals

\section{DISCUSSION}

Over the years, authors have been documenting several teeth having the most varied anatomical changes, one of them which happens to be premolars. The difference in anatomy (the number of root canal, its size, shape, divisions) may occur during tooth development stages and In most cases, the second premolars feature only one root and one canal. Post RCT, the presence of an untreated canal coupled with an inadequate debridement and incomplete obturation are a few common findings for failure of an endodontic treatment. ${ }^{7}$ A root canal may be left untreated because the dentist fails to recognize its presence on the radiograph as visualization of three canals in a maxillary premolar on pre-operative radiographs can often pose as a challenge. ${ }^{8,9}$

Pre-operative radiography gives us only a two dimensional (2D) image of a three dimensional object, a few some guides have been suggested that help in locating the presence of a third canal/root. It is stated that whenever an abrupt straightening or loss of radiolucent canal in the pulp cavity is observed, a third canal should be suspected, either in the same root or in the other independent root; also upon radiographic examination, whenever the mesio distal width of the mid root image is equal to or greater than the mesiodistal width of the crown, the tooth most likely has three roots. ${ }^{10}$ A simple rule is that if aberrant anatomy is seen it should be documented and checked by taking at least three radiographs from different angulations. ${ }^{11}$

\section{CONCLUSION}

It is the responsibility of the clinician to check for any aberrant root anatomy before commencing treatment to prevent any discomfort to the patient as well as prevent any undesirable consequences arising from a missed, untreated canal.

\section{REFERENCES}

1. Thakar SS, Motghare V, Prabhakar I, Shivlingesh KK, Gupta B, Gupta N. Bilateral Presence of a Single Root in Mandibular Second Molars having a Single NonConical Canal Configuration: A Rare Case Report. Int J Adv Health Sci 2014; 1(3): 31-4.

2. Pécora JD, Sousa Neto MD, Saquy PC, Woelfel JB. In vitro study of root canal anatomy of maxillary second premolars. Braz Dent J 1992;3(2):81-5.

3. Fava LR, Weinfeld I, Fabri FP, Pais CR. Four second molars with single roots and single canals in the same patient. Int Endod J 2002; 33(2): 138-42.

4. Hess W, Zürcher E, Dolamore WH. The anatomy of the root-canals of the teeth of the permanent dentition. J. Bale, Sons \& Danielsson, ltd. 1925

5. Vertucci FJ, Gegauff A. Root canal morphology of the maxillary first premolar. J Am Dent Assoc 1979;99(2):194-8.

6. Sieraski SM, Taylor GN, Kohn RA. Identification and endodontic management of three canalled maxillary premolars. J Endod 1989;15(1):29-32.

7. Grossman L. Endodontic failures. Dent Clin North Am. 1972;16:50-70.

8. Bander A, Majed A, Shatha A, et al. Maxillary first premolar with three canals. Smile Dent J. 2010;5(3):346.

9. Soares JA, Leornado RT. Root canal treatment of three rooted maxillary first and second premolars: A case report. Int. Endod. J. 2003;36:705-10.

10. Sulaiman AO, Dosumu OO, Amedari M. Maxillary First Premolar With Three Root Canals: A Case Report. Ann Ib Postgrad Med. 2013; 11(2):105-8.

11. Kumar T, Sanap A, Bhargava K, Aggarwal S, Kaur G, Patil P. Management of A Maxillary Premolar With Three Roots: A Case Report. Int J Cont Med Res. 2015;2(1):136-140. 
Source of support: Nil, Conflict of interest: None declared

Cite this article as:

Jain A, Gupta R. Three Rooted Maxillary Second Premolar: A Rare Clinical

Finding. Int Healthc Res J. 2018;2(7):165-167. doi: 10.26440/ihrj.v2i7.158

\section{AUTHOR AFFILIATIONS: \\ 1. BDS, Private Practitioner \\ 2. BDS, Private Practitioner}

*Corresponding Author:

Dr. Ajay Jain

H.No G-5/255

Vikaspuri

New Delhi
For article enquiry/author contact details, e-mail at:

manuscriptenquiry.ihrj@gmail.com 